\title{
Article \\ Oral Pathogenic Bacteria-Inducing Neurodegenerative Microgliosis in Human Neural Cell Platform
}

\author{
Van Thi Ai Tran ${ }^{1,2}{ }^{(}$, You Jung Kang ${ }^{3}$, Hyun-Kyoung Kim ${ }^{4}$, Hyung-Ryong Kim ${ }^{5, *(\mathbb{C}}$ and Hansang Cho ${ }^{1,2, *}$ \\ 1 Department of Biophysics, Institute of Quantum Biophysics, Sungkyunkwan University, Suwon 16419, Korea; \\ ttaivan@g.skku.edu \\ 2 Department of Intelligent Precision Healthcare Convergence, Institute of Quantum Biophysics, \\ Sungkyunkwan University, Suwon 16419, Korea \\ 3 Department of Mechanical Engineering and Engineering Science, University of North Carolina at Charlotte, \\ Charlotte, NC 28223, USA; ykang15@uncc.edu \\ 4 School of Pharmacy, Jeonbuk National University, Jeonju 54896, Korea; khkyoung11@jbnu.ac.kr \\ 5 College of Dentistry, Dankook University, Choenan 31116, Korea \\ * Correspondence: hrkimdp@gmail.com (H.-R.K.); h.cho@g.skku.edu (H.C.)
}

Citation: Tran, V.T.A.; Kang, Y.J.; Kim, H.-K.; Kim, H.-R.; Cho, H. Oral Pathogenic Bacteria-Inducing Neurodegenerative Microgliosis in Human Neural Cell Platform. Int. J Mol. Sci. 2021, 22, 6925. https:// doi.org/10.3390/ijms22136925

Academic Editor: Federico Licastro

Received: 26 May 2021

Accepted: 24 June 2021

Published: 28 June 2021

Publisher's Note: MDPI stays neutra with regard to jurisdictional claims in published maps and institutional affiliations.

Copyright: (c) 2021 by the authors. Licensee MDPI, Basel, Switzerland. This article is an open access article distributed under the terms and conditions of the Creative Commons Attribution (CC BY) license (https:// creativecommons.org/licenses/by/ $4.0 /)$.

\begin{abstract}
Porphyromonas gingivalis is a gram-negative bacterium found in the human oral cavity and is responsible for the development of chronic periodontitis as well as neurological diseases, including Alzheimer's disease (AD). Given the significance of the roles of $P$. gingivalis in AD pathogenesis, it is critical to understand the underlying mechanisms of $P$. gingivalis-driven neuroinflammation and their contribution to neurodegeneration. Herein, we hypothesize that $P$. gingivalis produces secondary metabolites that may cause neurodegeneration through direct or indirect pathways mediated by microglia. To test our hypothesis, we treated human neural cells with bacterial conditioned media on our brain platforms and assessed microgliosis, astrogliosis and neurodegeneration. We found that bacteria-mediated microgliosis induced the production of nitric oxide, which causes neurodegeneration assessed with high pTau level. Our study demonstrated the elevation of detrimental protein mediators, CD86 and iNOS and the production of several pro-inflammatory markers from stimulated microglia. Through inhibition of LPS and succinate dehydrogenase in a bacterial conditioned medium, we showed a decrease in neurodegenerative microgliosis. In addition, we demonstrated the bidirectional effect of microgliosis and astrogliosis on each other exacerbating neurodegeneration. Overall, our study suggests that the mouth-brain axis may contribute to the pathogenesis of AD.
\end{abstract}

Keywords: Alzheimer disease; microgliosis; neurodegeneration; Porphyromonas gingivalis; pathogenic bacteria

\section{Introduction}

Alzheimer's disease (AD) is the most common progressive neurodegenerative disease with clinical symptoms, such as memory loss at an early stage, that lead to a decline in the ability to respond to the living environment. Approximately 130 million people worldwide are estimated to be at risk of AD in 2050 according to the World Alzheimer Report 2015. Since the discovery of AD more than 100 years ago, several pathogenic mechanisms of AD have been proposed and the most recognized hypotheses relate to two distinctive protein markers, amyloid-beta $(\mathrm{A} \beta)$ and tau [1]. Moreover, oxidative stress and neuroinflammation have been proposed as the central mechanisms of neurodegeneration in AD [2].

A number of studies have demonstrated the connection between AD and neuroinflammation [3]. Inflammation and degeneration of brain cells that occur in the central nervous system have been linked to the accumulation of prion protein, including $A \beta$ and pTau, which are two known markers of AD [4]. Microglia and astrocytes are the most abundant brain immune cells and mainly contribute to neuroinflammatory processes in neurodegenerative diseases [5]. Neuroinflammation in AD is associated with M1/M2 
stage alterations in activated microglia, which are the major immune cells in the central nervous system [6]. Activated microglia cells change their morphologies, producing several proteins, pro-inflammatory cytokines, nitric oxide and reactive oxygen species [7].

Bacteria-mediated neuroinflammation has been considered a critical factor in neurodegeneration [8]. Bacterial lipopolysaccharide (LPS) and A $\beta$ are two well-known factors that can trigger chronic neuroinflammation, resulting in neurodegeneration related to neuronal death and astrogliosis [9]. Several bacterial species and their metabolites are mediators of neurodegenerative diseases [10] and, hence, the determination of specific bacterial species or bacteria-derived factors is essential to explore the role of bacteria in AD.

Porphyromonas gingivalis, commonly called gum bacteria, is an oral gram-negative anaerobe and a major pathogen of chronic periodontitis that is popular in both developed and developing countries, infecting approximately $20-50 \%$ of the global population with a high prevalence in adults and older people [11]. In a cohort study, chronic periodontitis patients had higher risks of dementia and $\mathrm{AD}$ than non-infected persons, which demonstrated the correlation of $\mathrm{AD}$ and periodontitis [12]. In addition, it has been reported that oral P. gingivalis treatment induced A $\beta 1-42$ levels, which are oligomeric forms of amyloid plaques, a well-known cause of $\mathrm{AD}$ and that small molecules called gingipains, which are toxic proteases, are associated with AD pathology [13]. Immunofluorescence labeling of LPS from P. gingivalis was conducted for AD brain specimens, which have contributed to understanding the relationship between gum bacteria and AD [14]. Current approaches have only been able to determine the effect of $P$. gingivalis on neuronal cells, but it is not clear if bacteria damage neurons directly or indirectly through activated microglia.

Therefore, we hypothesized that metabolites from $P$. gingivalis may trigger microgliosis and astrogliosis, which induce neuroinflammation, leading to neurodegeneration. In this study, we investigated the inflammatory roles of bacterial conditioned media in the activation of microglia and reactive astrocytes, which causes microgliosis and astrogliosis, as defined by immunostaining against several protein markers and measuring cytokines/chemokines released from stimulated cells. Our study demonstrated neurodegeneration by direct treatment with bacteria or indirectly through microgliosis to illustrate which mediators, bacteria or activated microglia, play a priority role in neurodegeneration. We also indicated the bidirectional interaction of microgliosis and astrogliosis and assessed microglial migration in brain-on-chip. Finally, we screened new metabolites from bacterial-conditioned media (BCM) as potential factors involved in neuroinflammation and demonstrated their cellular mechanisms.

\section{Results}

\subsection{Neurodegeneration Derived from Microgliosis and Astrogliosis-Induced Bacteria}

To investigate the effects of bacterial metabolites on innate immunity in the brain, we treated microglia, astrocytes and neurons isolated from patients with chronic periodontitis with $P$. gingivalis and assessed microgliosis, astrogliosis and neurodegeneration (Figure 1a). It should be noted that we employed two independent platforms, single-culture microglia and co-cultured neurons and astrocytes, to investigate neuroinflammation and neurodegeneration induced by BCM-stimulated microgliosis and astrogliosis.

For the first platform and to investigate the effect of $\mathrm{BCM}$ on the microglia directly, we seeded human adult microglia (SV40) in a single-culture platform and treated them with a mixture of microglial media and BCM at a ratio of 10:1 (10 MM:1 $\left.\mathrm{BCM}_{\mathrm{L} / \mathrm{H}}\right)$ for 3 days and investigated the microglial cell response. We immunostained microglia with antibodies targeting triggering receptors expressed on myeloid cells 2 (TREM-2), a pro-inflammatory marker (CD86) and inducible nitric oxide synthase (iNOS) to determine the phenotypes of the microglia. We also validated microglial activation in response to BCM using a multicytokine assay (Figure 1b) and a migration assay in a microfluidic chip (Figure 1c). We found that multiple cytokines were present in BCM, which can be crucial mediators of microglia activation at the M1 state. This induced CD86 level and further led to the release of more pro-inflammatory cytokines from the stimulated microglia. Our study 
demonstrated the pro-inflammatory activity of BCM characterized by strong level of the CD86 marker, which illustrated that $P$. gingivalis can stimulate the M1 activation state of microglia (Figure 1d).
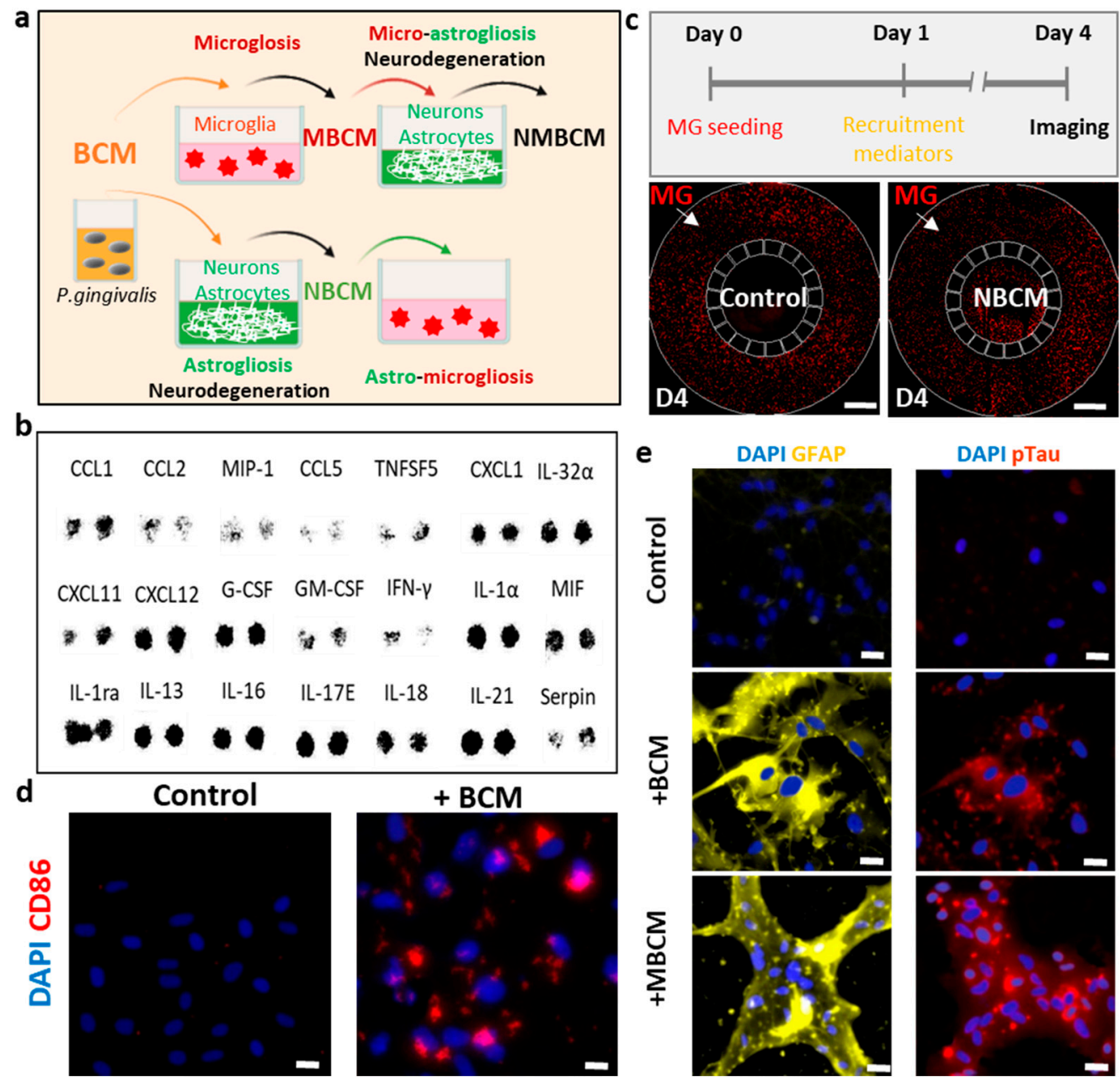

Figure 1. Utilization of human neural cells platforms to study neurodegenerative microgliosis induced by P. gingivalis infection. (a) Schematic of experimental design for assessment of microgliosis, astrogliosis and neurodegeneration under long-term exposure to bacterial conditioned media (BCM). (b) Multiple cytokines were detected in high-concentration $\mathrm{BCM}\left(\mathrm{BCM}_{\mathrm{H}}\right)$. (c) Representative results showing microglial recruitment on chip (Scale bar, $500 \mu \mathrm{m}$ ). (d) Representative images showing pro-inflammatory microglial marker (CD86) in control and BCM-stimulated microglia, scale bar $50 \mu \mathrm{m}$. (e) Representative images for reactive astrocytes (GFAP), neurodegenerative marker (pTau) of neurons/astrocytes in control, BCM and MBCM stimulation, scale bar $50 \mu \mathrm{m}$.

To test the indirect pathways, bacterial and stimulated-microglial conditioned media $\left(\mathrm{BCM}_{\mathrm{L} / \mathrm{H}}\right.$ and $\left.\mathrm{MBCM}_{\mathrm{L} / \mathrm{H}}\right)$ were employed to investigate if $P$. gingivalis could cause neurodegeneration directly from $\mathrm{BCM}$ or indirectly with microglia as an intermediate. Human neural progenitor cells (ReN) were differentiated for 21 days in neural media $(\mathrm{NM})$ and treated with four different conditions, including $\mathrm{BCM}_{\mathrm{L} / \mathrm{H}}$ and $\mathrm{MBCM}_{\mathrm{L} / \mathrm{H}}$. We labeled each media mixed with neural media and the $\mathrm{BCM}_{\mathrm{L} / \mathrm{H}}$ in the ratio of 100:1 as [100 NM:1 $\mathrm{BCM}_{\mathrm{L} / \mathrm{H}}$ ] and $\mathrm{MBCM}_{\mathrm{L} / \mathrm{H}}$ 10:1 as [10 NM:1 $\mathrm{MBCM}_{\mathrm{L} / \mathrm{H}}$ ] (Figure 1a). Stimulated microglial-conditioned media induced astrogliosis and neurodegeneration, as indicated by the induced level of the reactive astrocyte marker (GFAP) and neurodegenerative marker (pTau) (Figure 1e). Our results suggest that microglia are an important intermediate in neurodegeneration triggered by $P$. gingivalis. 


\subsection{Bacterial Conditioned Media Induced Microglial Inflammatory Responses}

We investigated the microglial phenotype in response to BCM. Microglial responses to LPS, $\mathrm{BCM}_{\mathrm{L}}$ and $\mathrm{BCM}_{\mathrm{H}}$ were assessed, as shown in Figure 2a. We first investigated the initial response of microglia to BCM by monitoring morphological changes. LPS was used as a positive control because it is known to strongly stimulate microglia [15]. Our data showed that morphological changes were observed in non-stimulated migroglia and LPS-/BCML-/H-stimulated cells. We also observed significant aggregation of the cells treated with LPS and $B C M_{L / H}$, compared with the non-treated cells (Figure $2 b$ ). To further validate microglial activation in response to $\mathrm{BCM}$, microglia were treated with $\mathrm{BCM}$ and immunostained with phenotypic markers of disease associated microglia (TREM-2) and M1 type microglia (CD86) (Figure 2b). The bacterial and LPS-stimulated microglia expressed increased TREM-2 levels, compared with non-stimulated cells. In particular, the TREM-2 levels in LPS-, $\mathrm{BCM}_{\mathrm{L}}$ - and BCMH-stimulated cells were almost 2.5-fold, 2.7-fold and 3-fold greater than that in the control, respectively (Figure 2c). We also found that the level of $\mathrm{CD}-86$ in $\mathrm{BCM}_{\mathrm{H}^{-}}, \mathrm{BCM}_{\mathrm{L}}$ - and LPS-treated microglia was significantly greater than that in the control cells (5-fold, 4-fold and 4-fold, respectively) (Figure 2d). Overall, these data indicate differences in microglial phenotype and responses between the control group and LPS $/ \mathrm{BCM}_{\mathrm{L} / \mathrm{H}^{-} \text {stimulated microglia. }}$

To further confirm the phenotype of microglia involved in neurodegeneration, microglia cells were immunostained with inducible nitric oxide synthase (iNOS) and the level of nitric oxide (NO), which is defined as one of the causes of neuroinflammation was measured [16]. We also quantified the levels of iNOS and NO and performed statistical analysis to determine statistical significance. According to the results, $\mathrm{BCM}_{\mathrm{H}}$-treated microglia expressed a significantly higher level of iNOS, which was 4.8 -fold greater than the control and 2.5-fold greater than LPS-and BCL-treated microglia (Figure 2e). BCM $\mathrm{H}_{\text {-stimulated }}$ microglia highly expressed NO, which was 3.7-fold, 2.2-fold and 2.4-fold higher than those in non-stimulated, LPS- and BCML-treated cells, respectively (Figure 2f). Next, we assessed the status of microglial inflammation by measuring multiple inflammatory cytokines in the MBCM (Figure 2g). The levels of cytokines, including IL-8, IL-18 and serpin, in $\mathrm{BCM}_{\mathrm{H}}$-stimulated microglia were significantly higher, at almost 7.5-fold, 3-fold and 2.8-fold, respectively, than those in non-stimulated cells (Figure 2h). Our data suggested that BCM induced microglial pro-inflammation, which may play a detrimental role in neuroinflammation, supporting our hypothesis that $\mathrm{BCM}$ can trigger microgliosis during $P$. gingivalis infection.

\subsection{Neurodegeneration Induced by Both Microglial and Bacterial Condition Media}

To demonstrate microgliosis-mediated neurodegeneration, co-cultured neurons and astrocyte-derived $\mathrm{hNPC}$ s were exposed to either $\mathrm{BCM}_{\mathrm{L} / \mathrm{H}}$ or $\mathrm{MBCM}_{\mathrm{L} / \mathrm{H}}$ (Figure 3a). We found notable morphological changes in the co-cultured neurons and astrocytes stimulated by $\mathrm{BCM}_{\mathrm{L} / \mathrm{H}}$ or $\mathrm{MBCM}_{\mathrm{L} / \mathrm{H}}$, compared with the non-treated cells (Figure $3 \mathrm{~b}$ ). In addition, GFAP levels increased in astrocytes stimulated by both $\mathrm{BCM}_{\mathrm{L} / \mathrm{H}}$ and $\mathrm{MBCM}_{\mathrm{L} / \mathrm{H}}$, representing the $\mathrm{BCM}$-and $\mathrm{MBCM}$-induced reactive astrocytes. We found that $\mathrm{BCM}_{\mathrm{H}}$-stimulated microglial-derived media showed nearly 9-fold higher GFAP level, compared with the controls, while the $\mathrm{BCM}_{\mathrm{H}}$-directed treatment caused a 7-fold increase in GFAP level (Figure 3c). In addition, treatment with $\mathrm{MBCM}_{\mathrm{L}}$ and $\mathrm{MBCM}_{\mathrm{H}}$ slightly increased GFAP level.

We next investigated the effect of conditioned media on neuronal cells. We found that neurons treated with $\mathrm{MBCM}_{\mathrm{L} / \mathrm{H}}$ exhibited higher pTau level than those treated with $\mathrm{BCM}_{\mathrm{L} / \mathrm{H}}$ treatment, indicating microgliosis and a higher AD risk [17]. Compared with non-stimulated neural cells, treatment with $\mathrm{MBCM}_{\mathrm{H}}$ and $\mathrm{BCM}_{\mathrm{H}}$ increased pTau levels by approximately 11.25 folds and 9.5 folds, respectively (Figure 3d). Our results demonstrated the association of $\mathrm{MBCM}_{\mathrm{L}}$ and $B C \mathrm{M}_{\mathrm{L}}$ with increase in $\mathrm{AD}$ risk, characterized by high pTau level. To determine cell viability, propidium iodide (PI) was used to stain dead cells, while DAPI was used to stain the nuclei of both dead and live cells. We then determined the population of dead cells (Figure 3e). The population of neurons and astrocytes treated with 
$\mathrm{BCM}$ and $\mathrm{MBCM}$ significantly decreased and the treatment with microglial conditioned media led to approximately $90 \%$ neuronal cell loss and the $\mathrm{BCM}_{\mathrm{H}}$ treatment resulted in almost $70 \%$ neuronal death. Moreover, the low concentration of bacterial and stimulated microglia-conditioned media $\left(\mathrm{BCM}_{\mathrm{L}}\right.$ and $\left.\mathrm{MBCM}_{\mathrm{L}}\right)$ reduced the population by $15 \%$. Both low and high concentrations of $\mathrm{BCM}$ and $\mathrm{MBCM}$ increased cell death of astrocytes and neurons, while $\mathrm{BCM}_{\mathrm{H}}$ and $\mathrm{MBCM}_{\mathrm{H}}$ were much more detrimental to the neurons/astrocyte population at high concentrations than at low concentrations. Taken together, our results indicate that neurodegenerative microgliosis is caused by bacterial infection in AD.
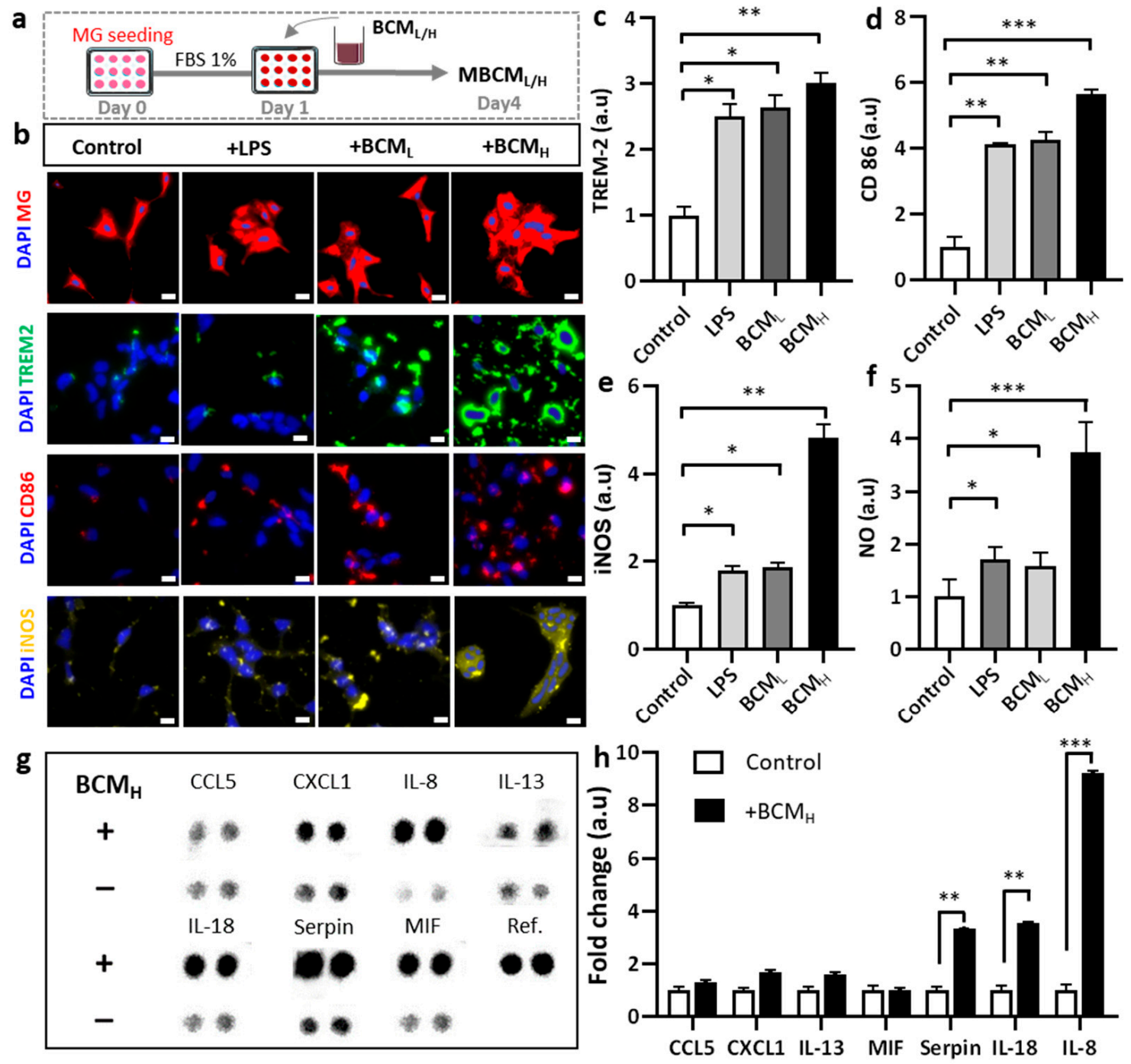

Figure 2. Assessment of neuro-inflammation trigged by bacterial conditioned media at two different concentrations. (a) Schematic diagram showing experimental timeline for neuro-inflammation assessment. (b) Morphological changes and immunostaining images against CD86, TREM-2 and iNOS markers of microglia cells treated with $10 \mathrm{ng} / \mathrm{mL}$ LPS, $\left[1 \mathrm{BCM}_{\mathrm{L}}: 10 \mathrm{MM}\right]$ and $\left[1 \mathrm{BCM}_{\mathrm{H}}: 10 \mathrm{MM}\right]$ in a single-culture system at day 4, scale bar $50 \mathrm{um}$. (c-e) Quantification of TREM2, CD86 and iNOS fluorescent intensity expressed by stained microglia cells. Significant differences among $\mathrm{BCM}_{\mathrm{L}}$, $\mathrm{BCM}_{\mathrm{H}}$ and LPS treatment, compared with the control. (f) Analysis of the amount of nitric oxide released by microglia cells. (g,h) Quantification of chemokines and cytokines released in microglia-stimulated conditioned media indicated increased inflammatory response from microglia cells, compared with the control. All experiments were repeated three times independently and statistically analyzed by One-way ANOVA followed by Tukey HSD test $\left(^{*} p<0.05,{ }^{* *} p<0.01\right.$ and *** $p<0.001)$. All data were presented as mean \pm standard deviation (SD). 


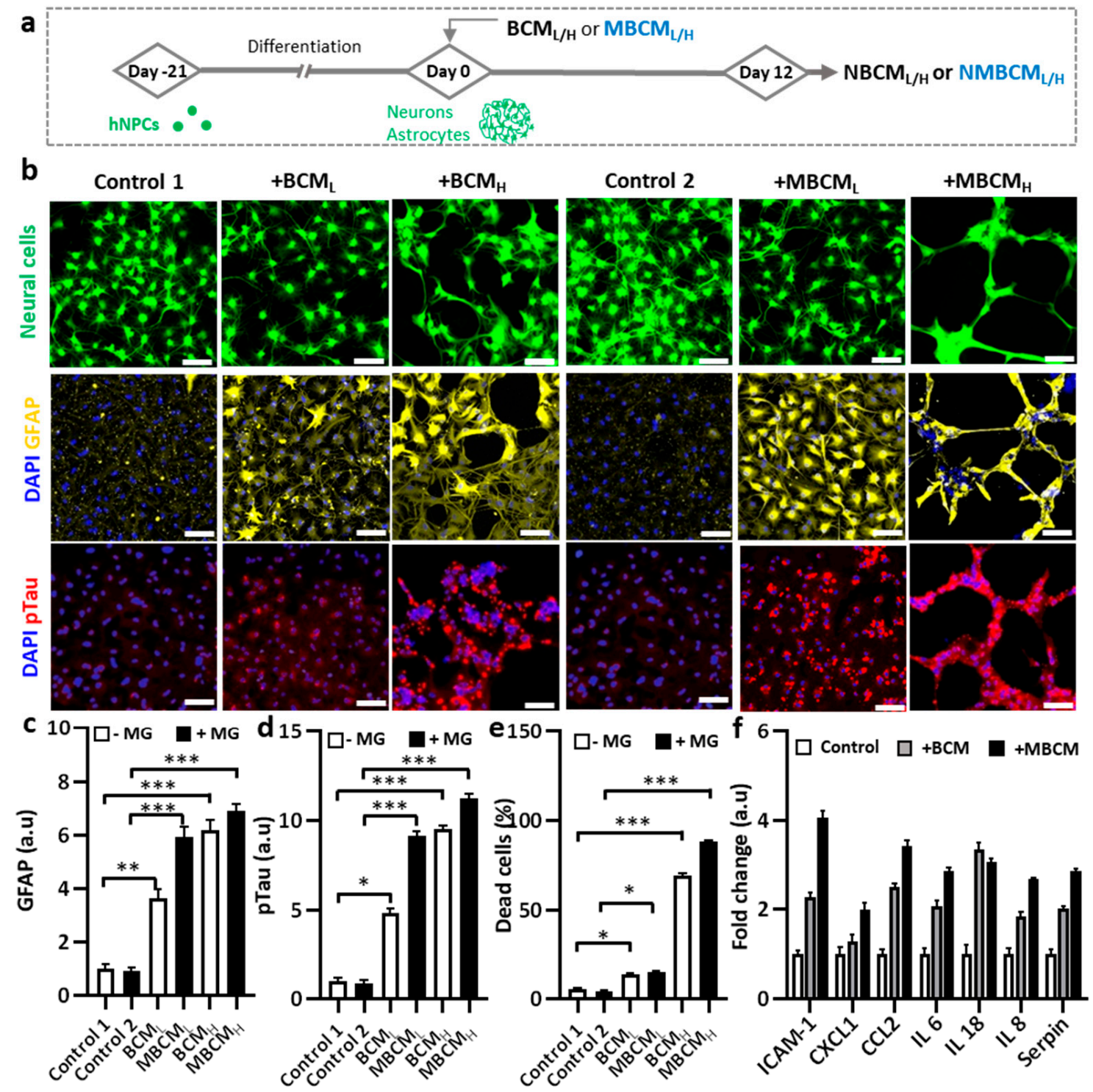

Figure 3. Neurodegeneration initiated by different bacteria-conditioned media $\left(\mathrm{BCM}_{\mathrm{L} / \mathrm{H}}\right)$ and microglia-derived media containing bacterial metabolites $\left(\mathrm{MBCM}_{\mathrm{L} / \mathrm{H}}\right)$. (a) Schematic diagram showing experimental timeline for astrogliosis and neurodegeneration. (b) Morphological changes in neurons/astrocytes (green) treated with bacterial conditioned media and microglia-stimulated conditioned media. Fluorescent images of GFAP and pTau staining of neurons/astrocytes after 12-day exposure. Scale bar, $100 \mu \mathrm{m}$. (c,d) Quantification of GFAP and pTau level in neurons/astrocytes. (e) Neural cells loss is quantified by measuring dead cell ratio. (f) Quantification of cytokines from astrocyte conditioned media. All experiments were repeated three times independently and statistically analyzed by One-way ANOVA followed by Tukey HSD test $\left({ }^{*} p<0.05,{ }^{* *} p<0.01\right.$ and $\left.{ }^{* *} p<0.001\right)$. All data were presented as mean \pm standard deviation (SD).

Next, we performed multiple cytokine detection to identify the cytokines in stimulated neurons/astrocyte-conditioned media. Conditioned media from non-stimulated, $\mathrm{BCM}_{\mathrm{H}}$-treated and $\mathrm{MBCM}_{\mathrm{H}^{-}}$-stimulated neurons/astrocytes were utilized for the detection. Multiple cytokines were detected, including CXCL1, IL-8, IL-6, Serpin, IL-18, CCL2 and ICAM-1 and the level of cytokines was normalized to that in non-stimulated cells. The $\mathrm{BCM}_{\mathrm{H}}$-treated cells generated more cytokines than the $\mathrm{MBCM}_{\mathrm{H}}$ cells, excluding IL-18 (Figure 3f). CCL2 was ranked second in the level, at more than 3.5-fold for $\mathrm{BCM}_{\mathrm{H}}$ and 2.5-fold for $\mathrm{MBCM}_{\mathrm{H}}$, compared with non-stimulated cells, which clarified why $\mathrm{NBCM}_{\mathrm{H}}$ recruited more microglia into the central chamber than $\mathrm{NMBC}_{\mathrm{H}}$. 


\subsection{Investigating the Interaction of Astrogliosis and Microgliosis}

After inducing neurodegeneration with $\mathrm{BCM}_{\mathrm{L} / \mathrm{H}}$ and $\mathrm{MBCM}_{\mathrm{L} / \mathrm{H}}$, we hypothesized that neuron-glia might have bidirectional influences on each other. Microgliosis involves the induction of loss of neurons/astrocytes (Figure 3) and astrogliosis may cause the activation of microglia, which means that microgliosis and astrogliosis may occur at the same time during infection and induce each other.

To test our hypothesis, conditioned media of neurons/astrocytes treated with $\mathrm{BCM}_{\mathrm{H}}$ or $\mathrm{MBCM}_{\mathrm{H}}$ were harvested $\left(\mathrm{NBCM}_{\mathrm{L} / \mathrm{H}}\right.$ or $\left.\mathrm{NMBCM}_{\mathrm{L} / \mathrm{H}}\right)$ and treated with the single-culture microglia (Figure 4a). To investigate the activation of microglia by astrogliosis, we monitored the morphological changes in microglia and the level of critical proteins representing microglial activation. Our results showed changes in the morphology of microglia treated with LPS and $\mathrm{NBCM}_{\mathrm{L} / \mathrm{H}}$, compared with the control. Next, microglia cells were stained against TREM-2, CD86, CD206 and iNOS to determine if stimulated microglia would exhibit a pro- or anti-inflammatory phenotype (Figure $4 \mathrm{~b}$ ). We found that microglia treated with NBCM showed higher TREM-2 level than those treated with LPS (Figure 4c). Interestingly, microglia treated with neurons/astrocyte-conditioned media co-expressed CD86 and CD206. $\mathrm{NBCM}_{\mathrm{H}}$-treated microglia cells showed a higher level of CD86 protein than LPS-treated and non-stimulated microglial cells, but at low concentration, a low CD86 level, which was not statistically different from that of non-stimulated cells, was observed (Figure $4 \mathrm{~d}$ ). In particular, the $\mathrm{NBCM}_{\mathrm{H}}$-stimulated microglia showed a 1.4-fold increase in CD86 level, in comparison with LPS-treated microglia, but a 5.7-fold increase, in comparison with non-stimulated microglia. With regard to the effect of low and high concentrations, $\mathrm{NBCM}_{\mathrm{H}}$ caused a 2.8-fold increase in CD86 level, compared with $\mathrm{NBCM}_{\mathrm{L}}$. Consistently, non-stimulated microglia showed higher level of anti-inflammatory protein markers than the treated cells, while microglia stimulated with LPS showed the lowest level of CD206 (Figure 4e). The level of CD206 in $\mathrm{NBCM}_{\mathrm{L}}$-treated microglia cells was 1.4-fold lower than that in non-stimulated cells. LPS and $\mathrm{NBCM}_{\mathrm{H}}$ caused a decrease in CD206 level, which was almost 5-fold lower than that in the control. Briefly, $\mathrm{NBCM}_{\mathrm{H}}$ induced pro-inflammatory protein markers better than $\mathrm{NBCM}_{\mathrm{L}}$, but greater anti-inflammatory activity was induced at the low concentration of conditioned media. In addition, microglia treated with neurons/astrocyte conditioned media significantly activated the iNOS pathway, compared with non-stimulated cells; in particular, $\mathrm{NBCM}_{\mathrm{H}}$ showed the best efficacy in the activation of iNOS, which was 3.2-fold higher than that of the control (Figure 4f). Consistently, $\mathrm{NBCM}_{\mathrm{H}}$-treated microglia generated higher levels of $\mathrm{NO}$ than $\mathrm{NBCM}_{\mathrm{H}}$-treated (2-fold) and LPS-treated cells (2.4-fold) (Figure 4g). Overall, our data showed that BCM-stimulated astrogliosis could also induce microglial activation.

\subsection{Microglial Migration and Investigation of New Bacterial Metabolites}

We utilized our established microfluidic model to assess microglial recruitment induced by three different conditioned media from previous experiments, including bacteriaconditioned media, stimulated microglia and stimulated neurons/astrocyte-derived culture media (Figure 1b). Microglia were seeded in the angular chambers and recruitment mediators were seeded in the central chamber. The recruited microglial cells were imaged and processed, which showed an increase in the number of cells on day 4 (Figure 5a). On day 2 , the number of recruited microglia by CCL2 and the three conditioned media was similar. However, slight differences occurred at day 4 with CCL2 being the most attractive (130 cells), followed by $\mathrm{NBCM}_{\mathrm{H}}$ (118 cells), while $\mathrm{BCM}_{\mathrm{H}}$ and $\mathrm{NMBCM}_{\mathrm{H}}$ achieved the same results (approximately 110 cells). CCL2 is one of the multiple cytokines detected in $\mathrm{BCM}_{\mathrm{H}}$-and $\mathrm{MBCMH}$-stimulated neurons/astrocytes and, hence, it is reasonable to explore its recruitment ability. 

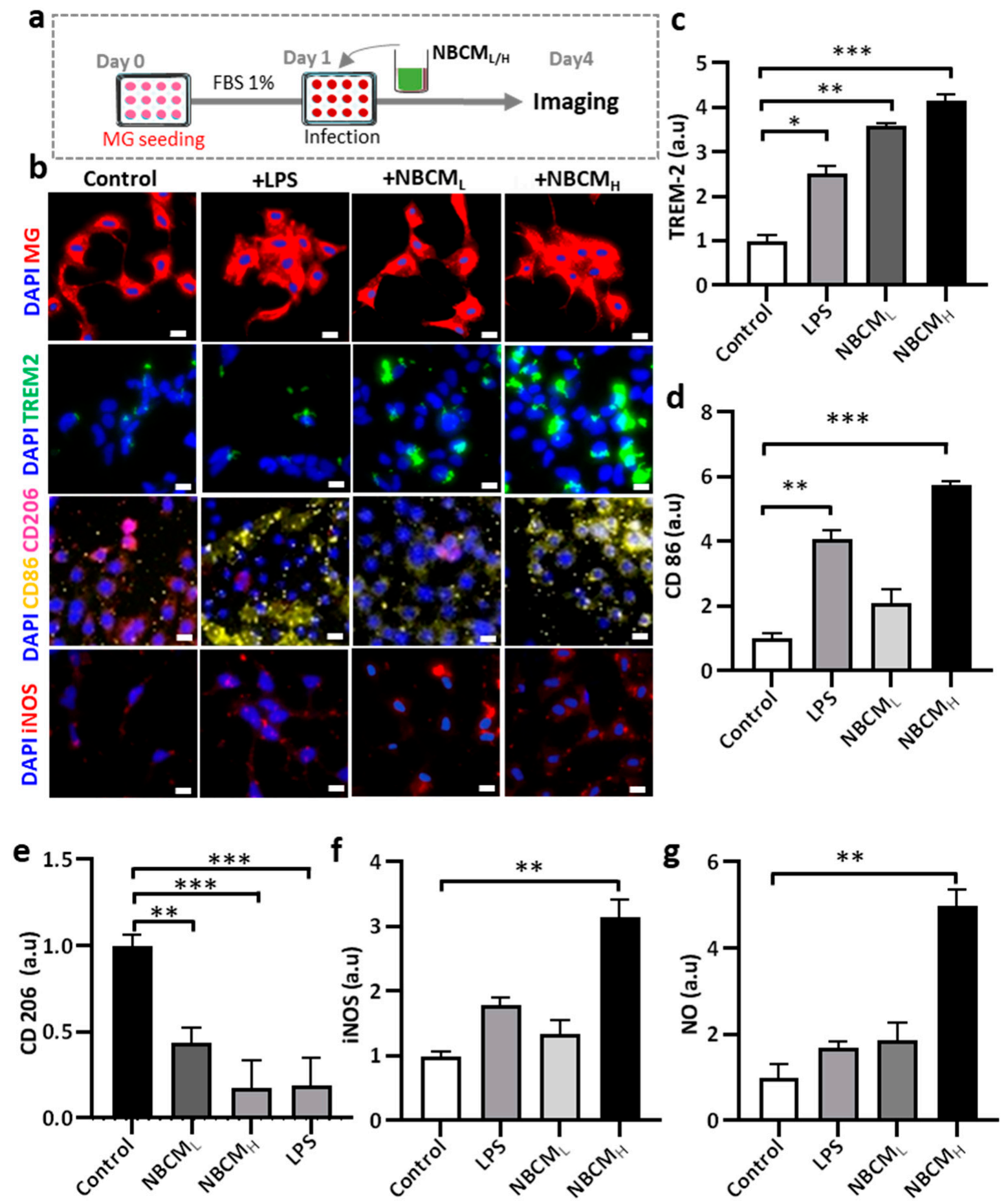

Figure 4. Neuron-glia interaction assessed by $\mathrm{BCM}_{\mathrm{L} / \mathrm{H}^{-}}$and $\mathrm{MBCM}_{\mathrm{L} / \mathrm{H}^{-}}$-stimulated neurons/astrocytes conditioned media. (a) Schematic diagram showing experimental timeline for investigating astrogliosis and microgliosis. (b) Morphological changes, immunostaining of SV40 microglia cell treated with $10 \mathrm{ng} / \mathrm{mL}$ LPS, [1 NBCM:10 MM] and [1 NMBCM:10 MM] against TREM-2, CD86, CD206 and iNOS in a single culture system. (c-f) Quantification of TREM-2, CD86, CD206 and iNOS in stimulated microglia. (g) Analysis of nitric oxide released by stimulated microglia. All experiments were repeated three times independently and statistically analyzed by One-way ANOVA followed by Tukey HSD test ${ }^{*} p<0.05,{ }^{* *} p<0.01$ and $\left.{ }^{* * *} p<0.001\right)$. All data were presented as mean \pm standard deviation (SD). 

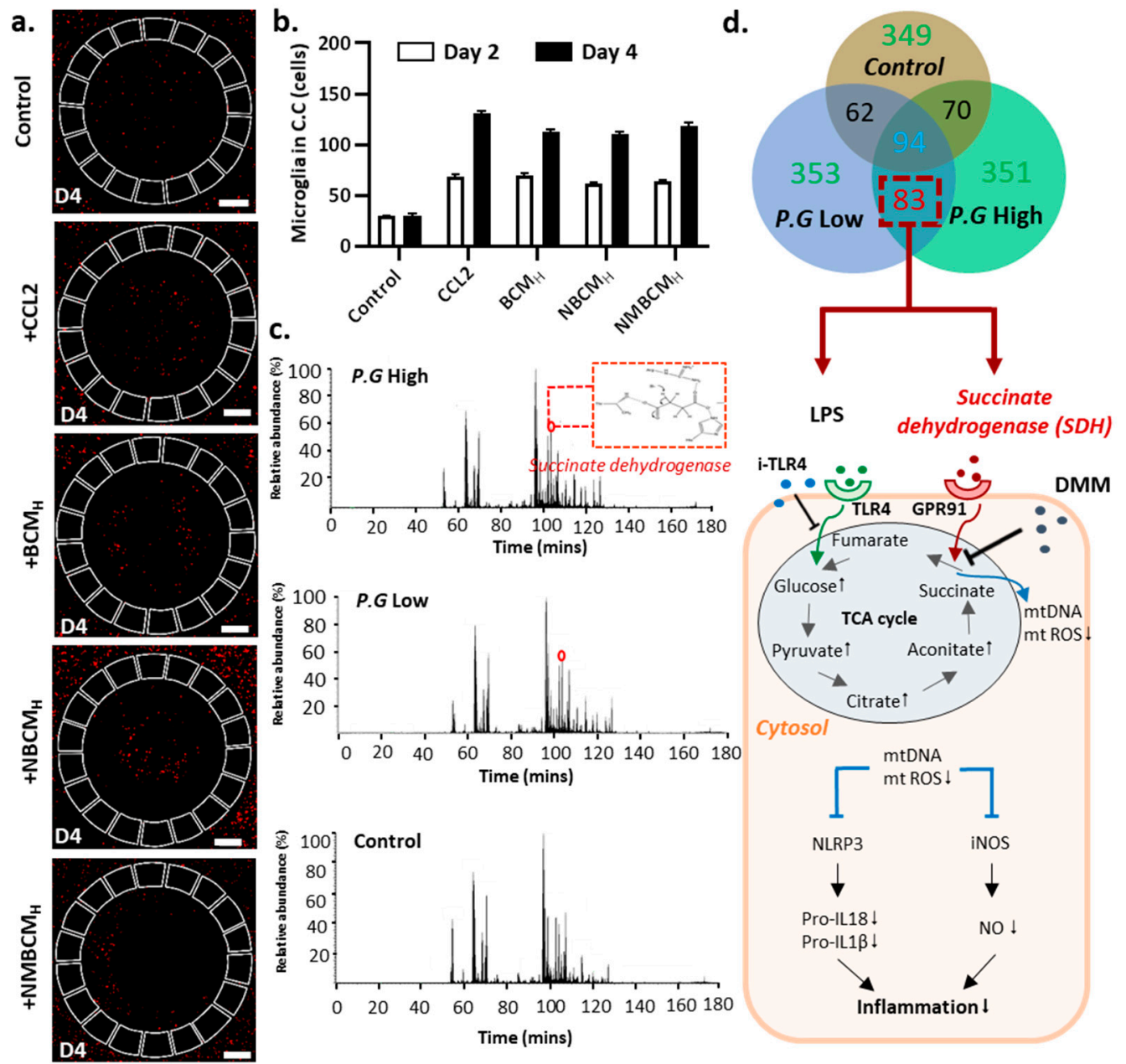

Figure 5. Microglial recruitment in microfluidic chip and investigation of new bacterial metabolites from the bacteria-conditioned medium. (a) Fluorescent images of microglial migration in brain-onchip upon different mediators. (b) Quantification of recruited microglial cells into the central chamber at day 2 and day 4. (c) The results of liquid chromatography-mass spectrometry (LC-MS) analysis of bacterial conditioned medium (high and low concentrations) and control. (d) Total compounds found in three samples, high/low concentration BCM and medium. The proposed cellular mechanism of how the inhibition of succinate dehydrogenase could reduce neuroinflammation in microglia. All experiments were repeated three times independently and statistically analyzed by One-way ANOVA followed by Tukey HSD test. All data were presented as mean \pm standard deviation (SD).

We next investigated how the recruited microglia contributed to neuroinflammation. To understand the underlying mechanisms of neuroinflammation driven by bacterial metabolites, we performed LC-MS analysis to investigate potential compounds that induce inflammation in the bacterial conditioned medium. Three different media, high and low concentrations of BCM and control, were analyzed using LC-MS (Figure 5c). After analysis, 349, 353 and 351 compounds were detected in the control, $\mathrm{BCM}_{\mathrm{H}}$ and $\mathrm{BCM}_{\mathrm{L}}$, respectively. Succinate dehydrogenase (SDH) is one of the 83 compounds found in both $\mathrm{BCM}_{\mathrm{H}}$ and $\mathrm{BCM}_{\mathrm{L}}$ and it is known to increase succinate oxidation, which upregulates the levels of nitric oxide and pro-inflammatory cytokines (Figure 5d). Upon LPS stimulation, microglia may induce glycolysis and increase the oxidation of succinate by the activities of SDH [18]. Co-stimulation might be the critical factor associated with the enhancement of microgliosis, which results in the loss and dysfunction of neuronal cells due to the upregulation of nitric oxide and pro-inflammatory cytokines. The inhibition of SDH with dimethyl malonate (DMM) may reduce the levels of mtDNA and mtROS released from 
damaged mitochondria, resulting in a decrease in inflammatory responses through the downregulation of pro-inflammatory cytokines and NO.

\subsection{Inhibition of SDH and LPS Reduces Microglial Inflammatory Responses}

We explored the cell-permeable molecule, DMM, which is rapidly hydrolyzed within the cell to generate malonate, a potent competitive inhibitor of SDH-induced succinate oxidation [19]. To test our hypothesis, we inhibited human TLR4 (hTLR4) to reduce LPS uptake and utilized DMM as an inhibitor of SDH upon stimulation of microglial cells by LPS and BCM (Figure 6a).

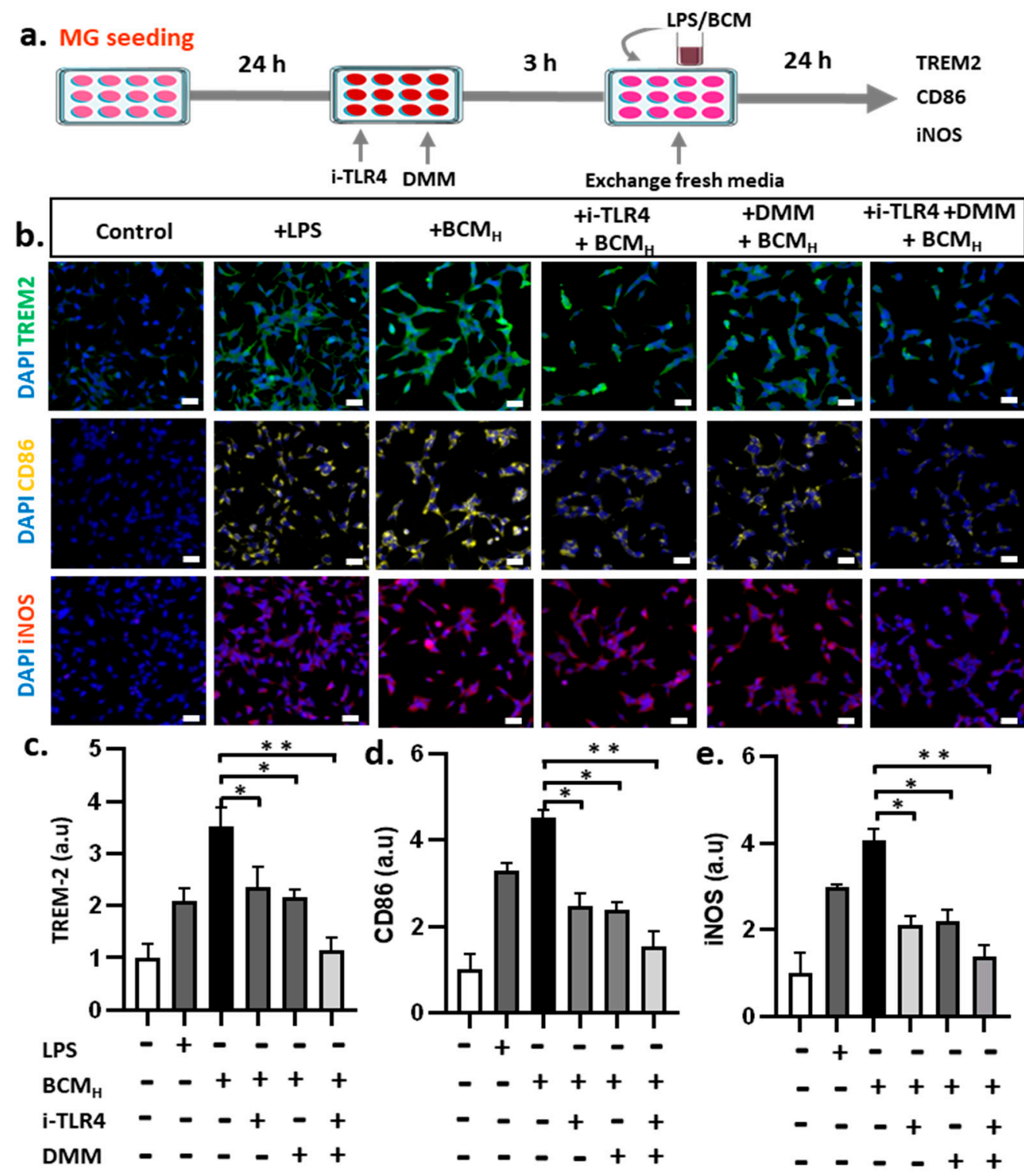

Figure 6. Inhibition of succinate dehydrogenase and LPS reducing microglial inflammatory responses. (a) Schematic showing experimental timeline for inhibition assay. (b) Immunostaining images against TREM-2, CD86 and iNOS markers of microglia cells. (c-e) Quantification of TREM2, CD86 and iNOS fluorescent intensity expressed by stained microglia cells. All experiments were repeated three times independently and statistically analyzed by One-way ANOVA followed by Tukey HSD test $\left({ }^{*} p<0.05,{ }^{* *} p<0.01\right)$. All data were presented as mean \pm standard deviation (SD).

To assess microglial responses to stimulators with single/co-inhibitors, the cells were immunostained with several protein markers, including TREM-2, CD-86 and iNOS (Figure 6b). TREM-2 level was decreased in cells treated with $\mathrm{BCM}_{\mathrm{H}}+\mathrm{hTLR} 4 / \mathrm{DMM}$ 
(Figure 6c). In comparison with the control, LPS and $\mathrm{BCM}_{\mathrm{H}}$ led to a 2-fold and 3.5-fold increase in TREM-2 level, respectively. After single and co-inhibition with hTLR4 and DMM, the level of TREM-2 decreased in treatments stimulated by BCM $\mathrm{H}_{\mathrm{H}}$. In particular, single inhibition with hTLR4 or DMM led to an almost 1.75-fold decrease in TREM-2 level from 3.5-fold to nearly 2-fold greater than that in the control. When co-inhibited with TLR4 and DMM, TREM-2 level was nearly the same as that in non-stimulated microglial cells. Similarly, there were significant changes in the level of CD86 in the inhibition treatments. Both individual and combined inhibition resulted in a decrease in CD86 levels upon BCM stimulation (Figure 6d). Microglial cells treated with LPS and BCM $\mathrm{H}_{\mathrm{H}}$ showed nearly 3-fold and 4.5-fold greater level of CD86, compared with non-stimulated cells, with significant

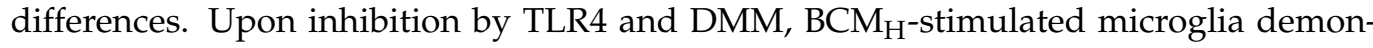
strated an almost 2-fold decrease in CD86 level in treatment with only TLR4 or DMM and a 2.5-fold decrease in combined inhibition. In addition, there were no significant differences in the cells treated with inhibitors and the control. Consistently, LPS-and BCMH-stimulated microglial cells increased the level of iNOS by almost 2.75 folds and 4 folds, respectively, compared with the control (Figure 6e). When we inhibited with only TLR4 or DMM upon $\mathrm{BCM}_{\mathrm{H}}$ stimulation, iNOS level was reduced from 4 fold to almost 2.5 fold in the individual inhibition and 1.5 fold in combined TLR4/DMM inhibition, compared with the control, without statistical significance. Based on this evidence, we can conclude that LPS and $\mathrm{SDH}$ are co-stimulators of neuroinflammation in microglia with $\mathrm{BCM}_{\mathrm{H}}$. The inhibition of either LPS or SDH slightly reduced microglial inflammatory responses, whereas combined inhibition showed a more significant reduction in microglial activation.

\section{Discussion}

Our study not only illustrates $P$. gingivalis-induced neurodegeneration as previously reported [13], but also demonstrates the critical role of microglia in response to bacterial infection in the central nervous system. This study directly connects three factors involved in $\mathrm{AD}$, including bacterial infection, neuroinflammation and neurodegeneration, using human neural cell culture platforms. Microglia are resident innate immune cells in the brain and are responsible for infection control and clearance of external pathogens [20]. $P$. gingivalis infection has been linked to microglia and neurodegeneration in AD in a mouse model [21]; however, the mechanism through which $P$. gingivalis alters microglial activity and causes neuroinflammation and neurodegeneration in humans remains unknown.

Neuroinflammation induced by bacterial or viral infection is considered a crucial player in the pathogenesis of AD [22]. TREM-2 is a protein expressed at the early and middle stages of AD and acts as an A $\beta$ receptor. TREM-2 level is upregulated in plaqueassociated microglia in both mice and humans [23]. We demonstrated that BCM triggered the level of TREM-2 in human microglia, which proved its association with AD. Microglia in the brain are highly plastic and can adopt distinctive phenotypes, including the classically activated (M1) and alternatively activated (M2) states in response to various simulations [24]. The M1 state of microglia is characterized by the production of proinflammatory cytokines and induced level of surface protein markers as well as inducible nitric oxide synthase, leading to NO generation [25]. The results of our study showed that $P$. gingivalis induced high level of CD86 protein (M1 marker) and iNOS as well as NO production, while multiple pro-inflammatory cytokines, including IL-8, IL-18, MIF and Serpin, which facilitated the inflammatory process, were also expressed. Interleukin- 8 (IL-8) is a pro-inflammatory cytokine produced by microglia, neurons and astrocytes and it is highly expressed in the serum, CSF and brain of AD patients [26]. A previous study reported an increase in IL-8 production in cultured microglia obtained post-mortem from AD and non-demented individuals [27]. In addition, CSF levels of IL-8 were significantly elevated in patients with mild cognitive impairment and in individuals diagnosed with AD, compared with age-matched controls [28].

Astrocytes can also initiate neuroinflammation, leading to neurodegeneration in Alzheimer's disease [29]. Astrocytes, the most abundant cells in the central nervous system, 
can be reactive during acute infection for clearance of pathogens and can induce neurological impairment [30]. Stimulation of reactive astrocytes can occur directly with $P$. gingivalis or through indirect pathways with microglia as an intermediate, which was demonstrated with bacterial conditioned media and bacterial-stimulated microglia condition media in our work. We observed the level of glial fibrillary acidic protein (GFAP), a common feature of reactive astrocytes, induced by bacterial and bacterial-stimulated microglia-conditioned media. Multiple cytokines detected in bacterial conditioned media are potential inflammatory mediators for astrocyte activation. A previous study indicated that iPSC-derived astrocytes stimulated by IL- $1 \beta$ generated much more IL- 8 and IL- 6 , compared with non-stimulated astrocytes [31], which is consistent with our results in which IL-8 and IL-6 were detected in stimulated neurons/astrocyte-conditioned media. In addition, microglia treated with bacterial conditioned media induce the level of several pro-inflammatory cytokines, such as IL-8, IL-18 and MIF, further leading to the formation of reactive astrocytes. A similar study demonstrated that pro-inflammatory cytokines produced by LPS-stimulated microglia are differentiation factors that promote the A1 phenotype of astrocytes, which are abundant in various human neurodegenerative diseases [32].

In this study, neuroinflammation-derived factors induced neurodegeneration after long-term exposure. Neurodegenerative microgliosis is associated with the loss of neuronal cells, alterations of phenotype and the level of pTau protein, which is a critical hallmark of AD. The generation of IL-8 from stimulated microglia and astrocytes can be the main factor in neurodegeneration due to its neurotoxic effects. Cell death was induced in neuronal cells treated with IL-8, which was associated with changes in pro-apoptotic proteins and inflammatory mediators [33]. In particular, bacterial-stimulated microglia demonstrated more significant results in neuronal loss than direct bacterial conditioned media treatment, which could be due to the high level of IL- 8 and other inflammatory cytokines from stimulated microglia and astrocytes. This study strongly demonstrated the critical role of microglia in neuroinflammation and neurodegeneration during $P$. gingivalis infection and pointed out that IL-8 released from stimulated microglia and astrocytes is the major neurotoxic cytokine in $P$. gingivalis infection, which contributes to the understanding of the role of the mouth-brain axis in AD.

\section{Materials and Methods}

\subsection{Preparation of Bacterial Conditioned Medium}

P. gingivalis was proliferated in Brain Heart Infusion (BHI) broth supplemented with hemin $(0.5 \mathrm{mg} / \mathrm{mL})$ and vitamin $\mathrm{K}(0.5 \mathrm{mg} / \mathrm{mL})$ until reaching $2.55 \times 10^{9} \mathrm{CFU} / \mathrm{mL}\left(\mathrm{BCM}_{\mathrm{L}}\right)$ and $7.62 \times 10^{10} \mathrm{CFU} / \mathrm{mL}\left(\mathrm{BCM}_{\mathrm{H}}\right)$. Bacterial cells were removed from the final conditioned media by centrifuging and filtering through $0.2 \mu \mathrm{m}$ membranes. The samples were stored at $-80^{\circ} \mathrm{C}$ for further experiments.

\subsection{Liquid Chromatography-Mass Spectrometry (LC-MS) Analysis}

The prepared samples were resuspended in $0.1 \%$ formic acid in water and analyzed using a Q-Exactive Orbitrap hybrid mass spectrometer (Thermo Fisher Scientific, Waltham, MA, USA) and an Ultimate 3000 system (Thermo Fisher Scientific, Waltham, MA, USA). We used a $2 \mathrm{~cm} \times 75 \mu \mathrm{m}$ ID trap column packed with $3 \mu \mathrm{m}$ C18 resin and a $50 \mathrm{~cm} \times 75 \mu \mathrm{m}$ ID analytical column packed with $2 \mu \mathrm{m} \mathrm{C} 18$ resin peptides depending on the hydrophobicity of the peptides. A data-dependent acquisition method was adopted and the top 10 precursor peaks were selected and isolated for fragmentation. Ions were scanned at high resolution (70,000 in MS1, 17,500 in MS2 at $m / z$ 400) and the MS scan range was 400-2000 m/z at both MS1 and MS2 levels. Precursor ions were fragmented using $27 \%$ normalized collisional energy (NCE). Dynamic exclusion was set to $30 \mathrm{~s}$. For proteome data analysis, MS/MS data obtained from the Thermo Q-Exactive instrument were converted to mzXML using MSConvert for searching in Andromeda of MaxQuant (version 1.5.8.3) (Martinsried, Germany). A cut-off probability score of less than $1 \%$ was used for the FDR. Information 
about the identified peptides and proteins was aligned using the mass of the charge state, retention time and peak area.

\subsection{Preparation of Membrane Stained-Microglia}

SV40 immortalized human adult microglia cells were purchased from Applied Biological Material Inc. (Montreal, Canada) and grown in T25 flasks (SPL Life Sciences Co., Ltd., Pocheon-si, Korea) containing microglia medium (MM), which comprised Pigrow III Medium (ABM Inc., Richmond, BC, Canada) supplemented with 10\% FBS (Life Technologies, Grand Island, NY, USA) at $37^{\circ} \mathrm{C}$ in the presence of $5 \% \mathrm{CO}_{2}$. The culture medium was changed every 2 days until the cells reached confluence. The membrane of the microglia was stained with red dye (PKH26PCL Red Fluorescence Cell Linker, Sigma Aldrich, St. Louis, MO, USA). The cells were detached using trypsin EDTA (Thermofisher Scientific, Waltham, MA, USA) and centrifuged at $1300 \mathrm{rpm}$ for $3 \mathrm{~min}$ to collect the cells. The pellets were instantly re-suspended in a mixture containing $1 \mathrm{~mL}$ of Diluent B (Sigma Aldrich, St Louis, MO, USA) and $4 \mu \mathrm{L}$ of dye solution. The mixture of cell/dye was incubated at room temperature for $10 \mathrm{~min}$ in the dark and periodically mixed to obtain uniform staining, after which $1 \mathrm{~mL}$ of $1 \%$ BSA in PBS was added to stop the dying process. Undyed cells and excess dye solution were eliminated by centrifuging twice at $1300 \mathrm{rpm}$ for $3 \mathrm{~min}$.

\subsection{Microglial Cells Culture Platform}

Membrane-stained microglia cells were seeded into Matrigel (BD Biosciences, San Jose, CA, USA)-coated 96 well-plates (Thermo Scientific, Seoul, Korea) at a density of 5000 cells/well. Positive controls were treated with $10 \mathrm{ng} / \mathrm{mL}$ LPS, while the treatment groups were treated with $\mathrm{BCMs}$ at $24 \mathrm{~h}$ after seeding. $\mathrm{BCM}$ was mixed with $\mathrm{MM}$ at a 1:10 ratio and microglial cultures were collected every 2 days, until the wells were confluent, for further analysis. Two groups of MBCM were collected for subsequent experiment: $\mathrm{MBCM}_{\mathrm{L}}$ and $\mathrm{MBCM}_{\mathrm{H}}$.

\subsection{Proliferation of Neurons/Astrocytes}

Human neural progenitor cells $(\mathrm{ReN})$ were purchased from EMD Millipore (Billerica, MA, USA) and grown in 1:100 Matrigel-coated T25 flasks (SPL Life Sciences Co., Pocheon-si, Korea). The flasks contained DMEM/F12 medium (Life Technologies, Grand Island, NY, USA) supplemented with $2 \mathrm{mg}$ heparin (Stemcell Technologies, Vancouver, BC, Canada), 2\% $(v / v)$ B27 (Life Technologies, Grand Island, NY, USA), 20 mg EGF (Sigma-Aldrich, St Louis, MO, USA), 20 mg bFGF (Stemgent, Cambridge, MA, USA) and 1\% $(v / v)$ PSA antibiotic solution (Lonza, Hopkinton, MA, USA). The culture medium was changed every 2 days until the cells reached confluence.

\subsection{Differentiation of Neurons/Astrocytes}

ReN cells were loaded into 96 well-plates coated with matrigel (1:100) at a density of $10^{4}$ cells/well supplemented with differentiation media for neuronal cells (NM). The differentiation media consisted of DMEM/F12 media (Life Technologies, Grand Island, NY, USA) supplemented with $2 \mathrm{mg}$ heparin (Stemcell Technologies, Vancouver, BC, Canada), $2 \%(v / v)$ B27 (Life Technologies, Grand Island, NY, USA) and 1\% $(v / v)$ antibiotic solution (Lonza, Hopkinton, MA, USA). After three weeks of differentiation, the cells were treated with bacteria and microglia-stimulated conditioned media. The experiment involved four treatment groups and two control groups.

\subsection{Microfluidic Chip Fabrication}

The microfluidic chip comprised three compartments, including an acrylic sheet at the top, a PDMS layer and a glass side at the bottom, which were fabricated by photolithography and soft lithography, as described in our previous study [34]. In brief, a mold was created by patterning negative photoresist SU-8 50 and SU-8 100 (MicroChem, Newton, MA, USA) onto a 4 inch silicon wafer to create microchannels with heights of $50 \mu \mathrm{m}$ and 
$100 \mu \mathrm{m}$ for cell migration and chemoattraction, respectively. The platform was generated by pouring a mixture of polydimethylsiloxane (PDMS) base and curing reagent at a 10:1 ratio (Sylgard 184 A/B, Dow Corning, Midland, MI, USA) into the mold, followed by vacuuming for $20 \mathrm{~min}$ to remove bubbles and incubation at $60^{\circ} \mathrm{C}$ for at least $4 \mathrm{~h}$ for full curing. Next, $2 \mathrm{~mm}$ holes were made into PDMS sheets. Acrylic thickness of $6 \mathrm{~mm}$ was prepared using a laser cutter (Zing 24, Epilog Laser, Golden, CO, USA) to array holes for the media reservoir. To combine the PDMS layer and acrylic, uncured PBMS:curing agent (10:1) was utilized as glue, followed by incubation at $60^{\circ} \mathrm{C}$ overnight. The glass slides and the assembled PDMS sheets were exposed to oxygen plasma at $50 \mathrm{~mW}$ and $5 \mathrm{~cm}$ for $30 \mathrm{~s}$ (PX-250, March Plasma System, Petersburg, FL, USA) and bonded together.

\subsection{Microglia Loading into the Microfluidic Chip}

SV40 cells were membrane-stained, as previously described, at a cell density of $5 \times 10^{5}$ cells $/ \mathrm{mL}$. Cells $(10 \mu \mathrm{L})$ were injected into each platform from the angular chambers, followed by incubation for $1 \mathrm{~h}$ at $37^{\circ} \mathrm{C}$ for cell adherence. Next, $100 \mu \mathrm{L}$ of culture medium supplemented with $1 \%$ FBS was added into two angular reservoir chambers. Microglial culture media supplemented with 1\% FBS (MM 1\%) and CCL2 $(10 \mathrm{ng} / \mathrm{mL})$ in $1 \% \mathrm{MM}$ were used as negative and positive controls, respectively. The dilution ratios of $\mathrm{BCM}_{\mathrm{H}}$ (100 fold) and $\mathrm{NBCM}_{\mathrm{H}}$ and $\mathrm{NMBCM}_{\mathrm{H}}(10$ fold $)$ synchronized with the ratio of bacterial conditioned media in the central chamber.

\subsection{Fluorescent Immunostaining}

When the cells reached confluence, they were washed twice with $1 \times$ PBS and fixed for $15 \mathrm{~min}$ at room temperature with $4 \%$ paraformaldehyde solution (Biosesang, Seongnam-si, Korea) and then rinsed twice with phosphate-buffered saline with $0.1 \%$ Tween ${ }^{\circledR} 20$ (PBST) twice to remove the excess fixing solution. For permeabilization, the cells were incubated with $0.1 \%$ Triton-X 100 in PBST for 15 min at RT and the blocking step was followed by incubation in 3\% BSA (BSA 100, Bovogen, Melbourne, VIC, Australia) for $1 \mathrm{~h}$ at room temperature. The samples were incubated with CD-86 (Ab239075, Abcam, Cambridge, MA, USA) and CD 206 (Abx140462, Abbexa Ltd., Cambridge, UK), iNOS (PA1-036, ThermoFisher scientific, Seoul, Korea) and TREM-2 (AF1828, R\&D System, Minneapolis, MN, USA) for microglia and with pTau (MN1020, ThermoFisher Scientific, Seoul, Korea) and GFAP (AB5541, EDM Millipore, Billerica, MA, USA) for neurons/astrocytes overnight at $4{ }^{\circ} \mathrm{C}$. Next, the samples were washed three times before incubation with secondary antibodies and DAPI for $1 \mathrm{~h}$ at RT. The samples were washed twice with PBST and the images were captured.

\subsection{Viability Assay}

Cells were stained with propidium iodide (P1304MP, Thermo Fisher Scientific, Seoul, Korea) for $15 \mathrm{~min}$ to detect dead cells. Next, the cells were washed thrice with PBS $1 \times$ to remove the excess dye. The cells were fixed in $4 \%$ paraformaldehyde solution, followed by DAPI staining for total nucleus recognition. PI and DAPI-stained cells were detected using a fluorescent microscope and the percentage of dead cells per total was determined using ImageJ software (Wayne Rasband, NIH).

\subsection{Nitric Oxide Measurement}

Nitric oxide (NO) released from microglia was measured using DAF-FM ${ }^{\mathrm{TM}}$ diacetate as an NO indicator (D-23844, Thermo Fisher Scientific, Seoul, Korea). A 5 nM stock solution was prepared by dissolving $50 \mu \mathrm{g}$ of DAF-FM ${ }^{\mathrm{TM}}$ diacetate in $20 \mu \mathrm{L}$ of high-quality anhydrous DMSO and the stock was diluted to $10 \mu \mathrm{M}$ in cell culture media. Microglia were prepared in a 96 well-plate and washed with PBS $1 \times$ once before exposure to the $\mathrm{NO}$ indicator. Next, the cells were incubated with $10 \mu \mathrm{M}$ DAF-FM ${ }^{\mathrm{TM}}$ diacetate at $37^{\circ} \mathrm{C}$ for $60 \mathrm{~min}$, followed by washing twice with PBS $1 \times$ to remove the excess probe. The old medium was replaced with fresh medium, followed by incubation for an additional $30 \mathrm{~min}$ 
to allow complete de-esterification of the intracellular diacetates. A fluorescent microscope was used to detect FITC signals from NO-indicated microglia.

\subsection{Detection of Multiple Cytokines}

A human multiple cytokine array kit was purchased from R\&D Systems, Minneapolis, MN, USA (Catalog\#ARY005) and utilized according to the manufacturer's protocol provided by the company. Briefly, the captured antibodies were spotted in duplicate on nitrocellulose membranes. Each sample $(0.5 \mathrm{~mL})$ was mixed with a cocktail of biotinylated detection antibodies. The sample/antibody mixture was then incubated with the array overnight at $4{ }^{\circ} \mathrm{C}$. Any cytokine/detection antibody complex was bound by its cognateimmobilized capture antibody on the membrane. Streptavidin-horseradish peroxidase (HRP) and chemiluminescent detection reagents were added. A signal is produced proportional to the amount of cytokine bound. Chemiluminescence was detected in the same manner as the western blot and the results were quantified using ImageJ software (Wayne Rasband, NIH).

\subsection{Inhibition Assay}

SV40 immortalized human adult microglia cells were seeded into matrigel-coated 96 well-plates at a density of 5000 cells/well. HumanTLR4 neutralization (Cat\#mabg-htlr4) was purchased from InvivoGen (San Diego, CA, USA) and dimethyl malonate (Cat\# 136441) was purchased from Sigma-Aldrich (St Louis, MO, USA). SV40 cells were pretreated with human TLR4 neutralization (hTLR4, $10 \mu \mathrm{g} / \mathrm{mL}$ ) or dymethyl malonate (DMM $5 \mathrm{mM}$ ) for $3 \mathrm{~h}$ before being stimulated with LPS $(10 \mathrm{ng} / \mathrm{mL})$ and [10 MM:1 $\left.\mathrm{BCM}_{\mathrm{H}}\right]$ for $24 \mathrm{~h}$.

\subsection{Fluorescence Imaging}

All fluorescent images were taken using a Nikon TiE microscope (Nikon, Japan) with a heated incubator at $37^{\circ} \mathrm{C}$ and $5 \% \mathrm{CO}_{2}$. Large images were taken with a $10 \times$ objective and $7 \times 7$ fields.

\subsection{Statistical Analysis}

All the data were analyzed using GraphPad Prism software (version 6) (San Diego, CA, USA). The differences among treatments were statistically tested using one-way analysis of variance followed by a post-hoc Tukey test. All data were normalized by control and presented as mean \pm standard deviation and $p<0.05$ indicated statistical significance. Symbols $\left({ }^{*}, * *, * *\right)$ denote significant differences between the groups.

Author Contributions: V.T.A.T. designed and performed all the experiments and statistical analysis, generated figures, as well as wrote and edited the manuscript. H.C. conceived the idea, provided guidance for all experiments and edited the manuscript. Y.J.K. contributed to the design of the experiments and edited the manuscript. H.-R.K. and H.-K.K. provided bacterial conditioned media and performed the LC-MS assay. All authors have read and agreed to the published version of the manuscript.

Funding: This research was funded by NRF-2020R1A2C2010285, NRF-2018M3C7A1056896, MOTIE20012352 (Ministry of Trade, Industry\& Energy, the Technology Innovation Program) (H.C.), NRF2017M3A9E4047243 (the Ministry of Science, ICT and Future Planning, the Bio \& Medical Technology Development Program) (H-R.K, H.C).

Institutional Review Board Statement: Not applicable.

Informed Consent Statement: Not applicable.

Data Availability Statement: The authors hereby declare that the data of this study will be presented upon request from the corresponding author.

Acknowledgments: We would like to thank Huyen Ngo, Minh Tran and Yen Diep for their kind contribution. 
Conflicts of Interest: The authors declare that the research was conducted in the absence of any commercial or financial relationships that could be construed as a potential conflict of interest.

\section{References}

1. Liu, P.P.; Xie, Y.; Meng, X.Y.; Kang, J.S. History and progress of hypotheses and clinical trials for alzheimer's disease. Signal. Transduct. Target. Ther. 2019, 4, 1-22. [CrossRef] [PubMed]

2. Kang, Y.J.; Diep, Y.N.; Tran, M.; Cho, H. Therapeutic targeting strategies for early-to late-staged alzheimer's disease. Int. J. Mol. Sci. 2020, 21, 9591. [CrossRef] [PubMed]

3. Hur, J.Y.; Frost, G.R.; Wu, X.; Crump, C.; Pan, S.J.; Wong, E.; Barros, M.; Li, T.; Nie, P.; Zhai, Y.; et al. The innate immunity protein IFITM3 modulates $\gamma$-secretase in Alzheimer's disease. Nature 2020, 586, 735-740. [CrossRef] [PubMed]

4. Busche, M.A.; Hyman, B.T. Synergy between amyloid- $\beta$ and tau in Alzheimer's disease. Nat. Neurosci. 2020, $23,1183-1193$. [CrossRef]

5. Ennerfelt, H.E.; Lukens, J.R. The role of innate immunity in Alzheimer's disease. Immunol. Rev. 2020, 297, 225-246. [CrossRef] [PubMed]

6. Leng, F.; Edison, P. Neuroinflammation and microglial activation in Alzheimer disease: Where do we go from here? Nat. Rev. Neurol. 2021, 17, 157-172. [CrossRef]

7. Gilhus, N.E.; Deuschl, G. Neuroinflammation-A common thread in neurological disorders. Nat. Rev. Neurol. 2019, 15, 429-430 [CrossRef]

8. Shen, H.; Guan, Q.; Zhang, X.; Yuan, C.; Tan, Z.; Zhai, L.; Hao, Y.; Gu, Y.; Han, C. New mechanism of neuroinflammation in Alzheimer's disease: The activation of NLRP3 inflammasome mediated by gut microbiota. Prog. Neuro-Psychopharmacol. Biol. Psychiatry 2020, 100, 109884. [CrossRef]

9. Batista, C.R.A.; Gomes, G.F.; Candelario-Jalil, E.; Fiebich, B.L.; de Oliveira, A.C.P. Lipopolysaccharide-induced neuroinflammation as a bridge to understand neurodegeneration. Int. J. Mol. Sci. 2019, 20, 2293. [CrossRef]

10. Angelucci, F.; Cechova, K.; Amlerova, J.; Hort, J. Antibiotics, gut microbiota, and Alzheimer's disease. J. Neuroinflamm. 2019, 16, 1-10. [CrossRef]

11. How, K.Y.; Song, K.P.; Chan, K.G. Porphyromonas gingivalis: An overview of periodontopathic pathogen below the gum line Front. Microbiol. 2016, 7, 53. [CrossRef]

12. Choi, S.; Kim, K.; Chang, J.; Kim, S.M.; Kim, S.J.; Cho, H.; Park, S.M. Association of Chronic Periodontitis on Alzheimer's Disease or Vascular Dementia. J. Am. Geriatr. Soc. 2019, 67, 1234-1239. [CrossRef]

13. Dominy, S.S.; Lynch, C.; Ermini, F.; Benedyk, M.; Marczyk, A.; Konradi, A.; Nguyen, M.; Haditsch, U.; Raha, D.; Griffin, C.; et al Porphyromonas gingivalis in Alzheimer's disease brains: Evidence for disease causation and treatment with small-molecule inhibitors. Sci. Adv. 2019, 5, eaau3333. [CrossRef] [PubMed]

14. Poole, S.; Singhrao, S.K.; Kesavalu, L.; Curtis, M.A.; Crean, S. Determining the Presence of Periodontopathic Virulence Factors in Short-Term Postmortem Alzheimer's Disease Brain Tissue. Adv. Alzheimers Dis. 2017, 5, 105-117. [CrossRef] [PubMed]

15. Zhao, J.; Bi, W.; Xiao, S.; Lan, X.; Cheng, X.; Zhang, J.; Lu, D.; Wei, W.; Wang, Y.; Li, H.; et al. Neuroinflammation induced by lipopolysaccharide causes cognitive impairment in mice. Sci. Rep. 2019, 9, 105-117. [CrossRef]

16. Wing, M.L.; Rettori, V.; Al-Shekhlee, A.; Bongiorno, P.B.; Canteros, G.; Mccann, S.M.; Gold, P.W.; Licinio, J. Inducible nitric oxide synthase gene expression in the brain during systemic inflammation. Nat. Med. 1996, 2, 581-584. [CrossRef] [PubMed]

17. Vogel, J.W.; Iturria-Medina, Y.; Strandberg, O.T.; Smith, R.; Levitis, E.; Evans, A.C.; Hansson, O. Spread of pathological tau proteins through communicating neurons in human Alzheimer's disease. Nat. Commun. 2020, 11, 2612. [CrossRef] [PubMed]

18. Mills, E.L.; Kelly, B.; Logan, A.; Costa, A.S.H.; Varma, M.; Bryant, C.E.; Tourlomousis, P.; Däbritz, J.H.M.; Gottlieb, E.; Latorre, I.; et al. Succinate Dehydrogenase Supports Metabolic Repurposing of Mitochondria to Drive Inflammatory Macrophages. Cell 2016, 167, 457-470. [CrossRef]

19. Dervartanian, D.V.; Veeger, C. Studies on succinate dehydrogenase. I. Spectral properties of the purified enzyme and formation of enzyme-competitive inhibitor complexes. Biochim. Biophys. Acta (BBA) Enzymol. Subj. 1964, 92, 233-247. [CrossRef]

20. Lehnardt, S. Innate immunity and neuroinflammation in the CNS: The role of microglia in toll-like receptor-mediated neuronal injury. Glia 2010, 58, 253-263. [CrossRef]

21. Liu, Y.; Wu, Z.; Nakanishi, Y.; Ni, J.; Hayashi, Y.; Takayama, F.; Zhou, Y.; Kadawaki, T.; Nakanishi, H. Infection of microglia with Porphyromonas gingivalis promotes cell migration and an inflammatory response through the gingipain-mediated activation of protease-activated receptor-2 in mice. Sci. Rep. 2017, 7, 1-13. [CrossRef]

22. Klein, R.S.; Garber, C.; Funk, K.E.; Salimi, H.; Soung, A.; Kanmogne, M.; Manivasagam, S.; Agner, S.; Cain, M. Neuroinflammation During RNA Viral Infections. Annu. Rev. Immunol. 2019, 37, 73-95. [CrossRef] [PubMed]

23. Shi, Y.; Holtzman, D.M. Interplay between innate immunity and Alzheimer disease: APOE and TREM2 in the spotlight. Nat. Rev. Immunol. 2018, 18, 759-772. [CrossRef] [PubMed]

24. Zhou, T.; Huang, Z.; Sun, X.; Zhu, X.; Zhou, L.; Li, M.; Cheng, B.; Liu, X.; He, C. Microglia polarization with M1/M2 phenotype changes in rd1 mouse model of retinal degeneration. Front. Neuroanat. 2017, 11, 77. [CrossRef] [PubMed]

25. Lan, X.; Han, X.; Li, Q.; Yang, Q.W.; Wang, J. Modulators of microglial activation and polarization after intracerebral haemorrhage. Nat. Rev. Neurol. 2017, 13, 420-433. [CrossRef] 
26. Alsadany, M.A.; Shehata, H.H.; Mohamad, M.I.; Mahfouz, R.G. Histone deacetylases enzyme, copper, and IL-8 levels in patients with Alzheimer's disease. Am. J. Alzheimers Dis. Other Demen. 2013, 28, 54-61. [CrossRef]

27. Lue, L.F.; Rydel, R.; Brigham, E.F.; Yang, L.B.; Hampel, H.; Murphy, G.M.; Brachova, L.; Yan, S.D.; Walker, D.G.; Shen, Y.; et al. Inflammatory repertoire of Alzheimer's disease and nondemented elderly microglia in vitro. Glia 2001, 35, 72-79. [CrossRef] [PubMed]

28. Buckley, P.F. Intrathecal Chemokine Synthesis in Mild Cognitive Impairment and Alzheimer Disease. Yearb. Psychiatry Appl. Ment. Health 2007, 2007, 303-304. [CrossRef]

29. Dorothée, G. Neuroinflammation in neurodegeneration: Role in pathophysiology, therapeutic opportunities and clinical perspectives. J. Neural Transm. 2018, 125, 749-750. [CrossRef]

30. Giovannoni, F.; Quintana, F.J. The Role of Astrocytes in CNS Inflammation. Trends Immunol. 2020, 41, 805-819. [CrossRef]

31. Santos, R.; Clark, A.T.; Gkountela, S.; Chen, D.; Liu, W.; Sosa, E.; Sukhwani, M.; Hennebold, J.D.; Orwig, K.E. Differentiation of Inflammation-Responsive Astrocytes from Glial Progenitors Generated from Human Induced Pluripotent Stem Cells. Stem Cell Rep. 2017, 9, 1-13. [CrossRef] [PubMed]

32. Liddelow, S.A.; Guttenplan, K.A.; Clarke, L.E.; Bennett, F.C.; Bohlen, C.J.; Schirmer, L.; Bennett, M.L.; Münch, A.E.; Chung, W.; Peterson, T.C.; et al. Neurotoxic reactive astrocytes are induced by activated microglia. Nature 2017, 541, 481-487. [CrossRef]

33. Thirumangalakudi, L.; Yin, L.; Rao, H.V.; Grammas, P. IL-8 induces expression of matrix metalloproteinases, cell cycle and pro-apoptotic proteins, and cell death in cultured neurons. J. Alzheimers Dis. 2007, 11, 305-311. [CrossRef] [PubMed]

34. Park, J.; Wetzel, I.; Marriott, I.; Dréau, D.; D'Avanzo, C.; Kim, D.Y.; Tanzi, R.E.; Cho, H. A 3D human triculture system modeling neurodegeneration and neuroinflammation in Alzheimer's disease. Nat. Neurosci. 2018, 21, 941-951. [CrossRef] [PubMed] 